\title{
O DESENVOLVIMENTO SUSTENTÁVEL DAS MICRORREGIÕES DO PARANÁ NOS ANOS 2000 E 2012*
}

\author{
Recebido: 23 de outubro de 2017 • Aprovado: 31 de outubro de 2018 \\ https://doi.org/10.22395/seec.v21n49a4
}

\author{
Samara Cristina Vieceli Piacenti** \\ Jandir Ferrera De Lima** \\ Carlos Alberto Piacenti ${ }^{* * * *}$
}

\section{RESUMO}

Este estudo analisa o perfil do desenvolvimento sustentável das 39 microrregiões do estado do Paraná, Brasil. Para cada microrregião, analisaram-se as dimensões ambiental, econômica, social e institucional. Para verificar a evolução e melhoria dos indicadores, foram utilizados dados de 2000 e 2012 no Painel de Sustentabilidade para gerar o Índice de Desenvolvimento Sustentável. Os resultados apontaram que a microrregião de Curitiba teve o melhor desempenho no desenvolvimento sustentável. No entanto, as microrregiões que mais se desenvolveram de 2000 a 2012 foram Pato Branco, Londrina e Ponta Grossa. Aquelas que menos se desenvolveram nesse período foram as de Jaguariaíva, São Mateus do Sul, Prudentópolis e Lapa.

\section{PALAVRAS-CHAVE}

Desenvolvimento sustentável; painel de sustentabilidade; economia regional; economia paranaense.

\section{CLASIFICAÇÃO JEL}

\author{
O18, Q01, Q56
}

\section{CONTEÚDO}

Introdução; 1. Referencial teórico; 2. Procedimentos metodológicos; 3. Análise do Índice de Desenvolvimento Sustentável (IDS) das microrregiões paranaenses; 4. Conclusão; Referências.

* Este é um artigo de investigação. Foi um projeto de iniciação científica originário do trabalho de conclusão de curso de Ciências Econômicas em 2014, da Universidade Estadual do Oeste do Paraná (UNIOESTE), Toledo, Paraná, Brasil, o qual ganhou o $1^{\circ}$ lugar do $25^{\circ}$ Prêmio Paraná de Economia em 2015.

* Economista pela Universidade Estadual do Oeste do Paraná, Toledo, Brasil. Mestranda em Desenvolvimento Regional e Agronegócio na Universidade Estadual do Oeste do Paraná, Toledo, Brasil. Endereço: Rua da Faculdade, n. 645, bairro Jardim La Salle. Correio eletrônico: samara_cv_@ @hotmail. $\underline{\mathrm{com}}$

*.. Economista pela Universidade de Cruz Alta, Cruz Alta, Brasil. Mestre em Economia pela Universidade Federal da Bahia, Salvador, Brasil. Doutor em Desenvolvimento Regional pela Universidade do Québec, Saguenay, Canadá. Professor do Programa de Pós-graduação em Desenvolvimento Regional e Agronegócio da Universidade Estadual do Oeste do Paraná, Toledo, Brasil. Endereço: Rua da Faculdade, n. 645, bairro Jardim La Salle. Correio eletrônico: jandirbr@yahoo.ca; jandir.lima@unioeste.br

*** Economista pela Faculdade de Ciências Econômicas do Sul de Minas, Itajubá, Brasil. Mestre em Economia Rural pela Universidade Federal de Viçosa, Viçosa, Brasil. Doutor em Economia Aplicada pela Universidade de Viçosa, Viçosa, Brasil. Professor do Programa de Pós-graduação em Desenvolvimento Regional e Agronegócio da Universidade Estadual do Oeste do Paraná, Toledo, Brasil. Endereço: Rua da Faculdade, n. 645, bairro Jardim La Salle. Correio eletrônico: piacenti8@yahoo.com.br 


\title{
EL DESARROLLO SOSTENIBLE DE LAS MICRORREGIONES DE PARANÁ EN LOS AÑOS 2000 Y 2012
}

\section{RESUMEN}

Este estudio analiza el perfil de desarrollo sostenible de las 39 microrregiones del departamento de Paraná, Brasil. Para cada microrregión, se analizaron las dimensiones ambientales, económica, social e institucional. Para verificar la evolución y mejora de los indicadores se utilizaron datos de 2000 y 2012 en el Panel de Sostenibilidad para generar el Índice de Desarrollo Sostenible. Los resultados indicaron que la microrregión de Curitiba obtuvo el mejor desempeño en el desarrollo sostenible. Sin embargo, las microrregiones que más se desarrollaron de 2000 a 2012 fueron Pato Branco, Londrina y Ponta Grossa, mientras las que menos presentaron desarrollo fueron las de Jaguariaíva, São Mateus do Sul, Prudentópolis y Lapa.

PALABRAS CLAVE

Desarrollo sostenible; panel de sostenibilidad; economía regional; economía paranaense.

\section{CLASIFICACIÓN JEL}

O18, Q01, Q56

\section{CONTENIDO}

Introducción; 1. Referencial teórico; 2. Procedimientos metodológicos; 3. Análisis del Índice de Desarrollo Sostenible (IDS) de las microrregiones paranaenses; 4. Conclusiones; Referencias.

\section{THE SUSTAINABLE DEVELOPMENT OF MICROREGIONS FROM PARANÁ DURING THE YEARS OF 2000 AND 2012}

\begin{abstract}
This article studies the sustainable development profile of 39 microregions in the state of Paraná, Brazil. For each microregion, we analyzed the environmental, economic, social and institutional dimensions. In order to verify the indicators evolution and improvement, we used data from 2000 and 2012 in the Sustainability Panel to generate the Sustainable Development Index. The results show that the microregion of Curitiba had the best performance in sustainable development. However, the most developed microregions from 2000 to 2012 were Pato Branco, Londrina and Ponta Grossa, whereas the least developed ones were Jaguariaíva, São Mateus do Sul, Prudentópolis and Lapa.
\end{abstract}

\section{KEYWORDS}

Sustainable development; sustainability panel; regional economy, Paraná economy.

\section{JEL CLASSIFICATION}

O18, Q01, Q56

\section{CONTENTS}

Introduction; 1 . Theoretical reference; 2. Methodology; 3. Analysis of Sustainable Development Index (SDI) from Paraná microregions; 4. Conclusions; References. 


\section{INTRODUÇÃO}

Segundo Alves e Ferrera de Lima (2007), conciliar o crescimento econômico com o desenvolvimento sustentável é encontrar formas menos prejudiciais ao meio ambiente para se desenvolver. O que não é uma tarefa fácil. O desafio propõe mudanças nas relações econômicas, ambientais, sociais, pessoais, culturais, de consumo, entre outras.

Segundo Bourscheidt e Dalcomuni (2010), o desenvolvimento econômico era considerado por algumas correntes do pensamento econômico sinônimo de crescimento econômico. Para se desenvolver, era preciso aumentar as quantidades da produção, elevar o lucro e a riqueza material. No entanto, a partir da década de 1960, consequências negativas foram notadas no meio ambiente, o que levou a que isso mudasse.

Desde então, o tema desenvolvimento sustentável ganhou importância em escala global; a preocupação aumentou em favor de meios menos danosos para manter os níveis de produção em constante crescimento quantitativo, qualitativo e tecnológico.

A definição mais aceita para desenvolvimento sustentável surgiu na Commission Brundtland (1987), que o define como aquele capaz de suprir as necessidades da geração atual, sem comprometer a capacidade de atender às necessidades das futuras gerações. É o desenvolvimento que não esgota os recursos para o futuro. Na mesma linha de raciocínio, McDonough (1992) diz que a ideia de sustentabilidade foi introduzida com a intenção de conciliar o bem-estar do planeta com o crescimento e o desenvolvimento humano.

Assim, este estudo analisa a situação do índice de sustentabilidade do estado do Paraná, Brasil, como forma de avaliar o ritmo de desenvolvimento das regiões do estado em relação ao aspecto social e econômico, mas também ambiental e institucional. Em específico, analisa-se o perfil do desenvolvimento sustentável nas dimensões ambiental, econômica, social e institucional, comparam-se os Índices de Desenvolvimento Sustentável (IDS) e analisa-se o desempenho do IDS das microrregiões para os anos 2000 e 2012.

O método para realizar as análises foi o Painel de Sustentabilidade, que compara os dados das microrregiões entre si. Com base nos resultados, buscou-se responder aos seguintes questionamentos: as microrregiões paranaenses avançaram em termos de desenvolvimento sustentável? Como foi esse desempenho? Quais foram as variáveis que mais impactaram no perfil do desenvolvimento sustentável? 
Devido à análise ter sido feita por microrregiões (MRGs), foi possível notar a desigualdade entre elas, quais já estão mais desenvolvidas e quais precisam se desenvolver para que o estado avance no IDS.

Os resultados indicam que, em 2000, a situação do desenvolvimento sustentável das MRGs era muito ruim. A MRG mais desenvolvida no período 2000-2012 foi a de Curitiba, capital do Estado, cujo desempenho foi razoável, enquanto as MGR menos desenvolvidas no período foram as de Pitanga e de Cerro Azul, ambas saindo de estado crítico para estado péssimo. Em geral, os resultados obtidos para o ano 2012 indicaram que as MGR se equilibraram um pouco nas quatro dimensões em relação ao período de 2000.

Este trabalho é composto por quatro seções além desta introdução. A segunda seção é composta por um referencial teórico, que abrange os conceitos de desenvolvimento sustentável; a terceira seção explica os procedimentos metodológicos; a quarta é composta pela discussão dos resultados e, por fim, a conclusão do estudo na última seção.

\section{REFERENCIAL TEÓRICO}

Para Bossel (1999), os indicadores são classificados em dois grupos: os que fornecem informações vitais para a formação de uma imagem de como está o sistema atual e os que fornecem informações suficientes para contribuir no desempenho de outros sistemas que dependem delas. O quadro de indicadores utilizado neste estudo se encontra no primeiro grupo e toma como referência o modelo de quatro dimensões do desenvolvimento sustentável, proposto pelo Instituto Brasileiro de Geografia e Estatística (IBGE) (2012). O estudo utilizou a seguinte base de dados descrita a seguir.

- Dimensão ambiental: uso dos recursos naturais, degradação ambiental e metas de preservação do meio ambiente, aspectos considerados essenciais para a qualidade de vida da atual geração e das gerações futuras.

- Dimensão social: busca demonstrar o nível educacional, a distribuição da renda, os assuntos relacionados à equidade e as condições de vida da população, indicando a direção de sua evolução.

- Dimensão econômica: utilização e esgotamento dos recursos naturais, produção e gestão de resíduos, uso de energia e sua ligação com o desemprego macroeconômico e financeiro nacional. Essa dimensão abrange eficiência dos processos produtivos e alterações de consumo orientadas a uma reprodução econômica sustentável de longo prazo. 
- Dimensão institucional: relacionada à orientação política, à capacidade e ao esforço realizado com governos e com a sociedade na implantação das mudanças requeridas para uma efetiva implantação do desenvolvimento sustentável.

Bossel (1999) afirma que indicadores resumem informações complexas em valores. Eles condensam a complexidade em uma quantidade de informações significativas em um subconjunto de observações que auxiliam nossas decisões e direcionam nossas ações. Ao se analisarem indicadores relevantes, é possível entender e lidar com o ambiente dinâmico. Saber manusear um complexo sistema significa reconhecer um conjunto específico de indicadores e o seu significado para a sustentabilidade do sistema.

\subsection{Painel de Sustentabilidade (Dashboard of Sustainability)}

Para Van Bellen, (2003) e Benetti, (2006), o Painel de Sustentabilidade é um sistema que gera um índice de sustentabilidade. Mensura-se a sustentabilidade no sistema calculando a média de vários indicadores com pesos iguais, organizados em quatro categorias de desempenho: econômica, social, ambiental e institucional. O painel exibe-se através de uma escala de cores que varia do vermelho-escuro (situação crítica), passando pelo amarelo (mediana) até chegar ao verde-escuro (excelente). Como os resultados são demonstrados por dimensão e não apenas o crescimento econômico, considera-se uma análise de desenvolvimento efetivo que leve em julgamento a necessidade de ser socialmente justo, economicamente viável e ambientalmente responsável.

Segundo Van Bellen (2003), o sistema foi inicialmente operacionalizado para comparação de países a partir de 46 indicadores que compunham três dimensões: meio ambiente, com 13 indicadores; econômica, com 15 indicadores, e social, com 18 indicadores. Esses indicadores formam a base de dados do Grupo Consultivo sobre IDS, que cobria aproximadamente 100 nações.

As pesquisas para a criação do software iniciaram em 1996, e o método foi lançado apenas em 1999, quando houve o desafio de se desenvolver um índice prático de sustentabilidade. Segundo Benetti (2006), a Fundação Global Wallace, com colaboração de especialistas de todos os continentes, criou, em 1996, um grupo consultivo com o objetivo de promover a cooperação e estratégias entre indivíduos e instituições-chave. Esse grupo trabalha no desenvolvimento e na utilização de indicadores de desenvolvimento sustentável. 


\subsection{Ecodesenvolvimento e desenvolvimento sustentável}

De acordo com Layrargues (1997), ecodesenvolvimento é uma forma de desenvolvimento temporal, no qual as necessidades da geração futura devem ser garantidas. Embasa-se na utilização ponderada dos recursos locais, o que impede o esgotamento da natureza, e enfatiza ainda a importância de se tomar conhecimento das diferentes culturas e ecossistemas, assim como a forma que as pessoas se relacionam com o meio ambiente.

Para Romeiro, Reydon e Leonardi (1999), o ecodesenvolvimento é similar ao desenvolvimento sustentável, no sentido que os direitos de equidade social e a consciência ecológica, com sensatez, caminhem alinhadas, delimitando entre as atividades econômicas à parte daquelas que suscitam o verdadeiro desenvolvimento.

Jara (1998) complementa que o desenvolvimento sustentável se refere aos processos de mudança sociopolítica, socioeconômica e institucional que visam garantir a satisfação das necessidades básicas e a equidade social.

A pobreza generalizada não é considerada inevitável pelo relatório Brundtland. Conforme Barbosa (2008), o relatório considera que, para uma região se desenvolver, deve-se priorizar as necessidades básicas e oferecer oportunidades de melhoria de qualidade de vida à população. Um dos conceitos mais discutido pelo relatório foi o de equidade, em que a sociedade deve participar das tomadas de decisões para o desenvolvimento urbano.

\section{PROCEDIMENTOS METODOLÓGICOS}

A ferramenta utilizada para comparar as variáveis em termos de crescimento e desenvolvimento foi o Dashboard of Sustainability (Painel de Sustentabilidade). Cada dimensão teve até seis variáveis. O software compara todas as regiões, levando em conta os maiores e os menores dados registrados como parâmetro de melhor e pior situação de desenvolvimento em cada período.

A representação gráfica do Painel de Sustentabilidade usou até quatro displays. Cada display apresentou a pontuação da região analisada por suas quatro dimensões (Figura 1). Para identificar o desempenho de cada indicador em cada dimensão, foi adotada uma escala de cores que representa um índice (Figura 2). 
Figura 1. Apresentação gráfica do Painel de Sustentabilidade

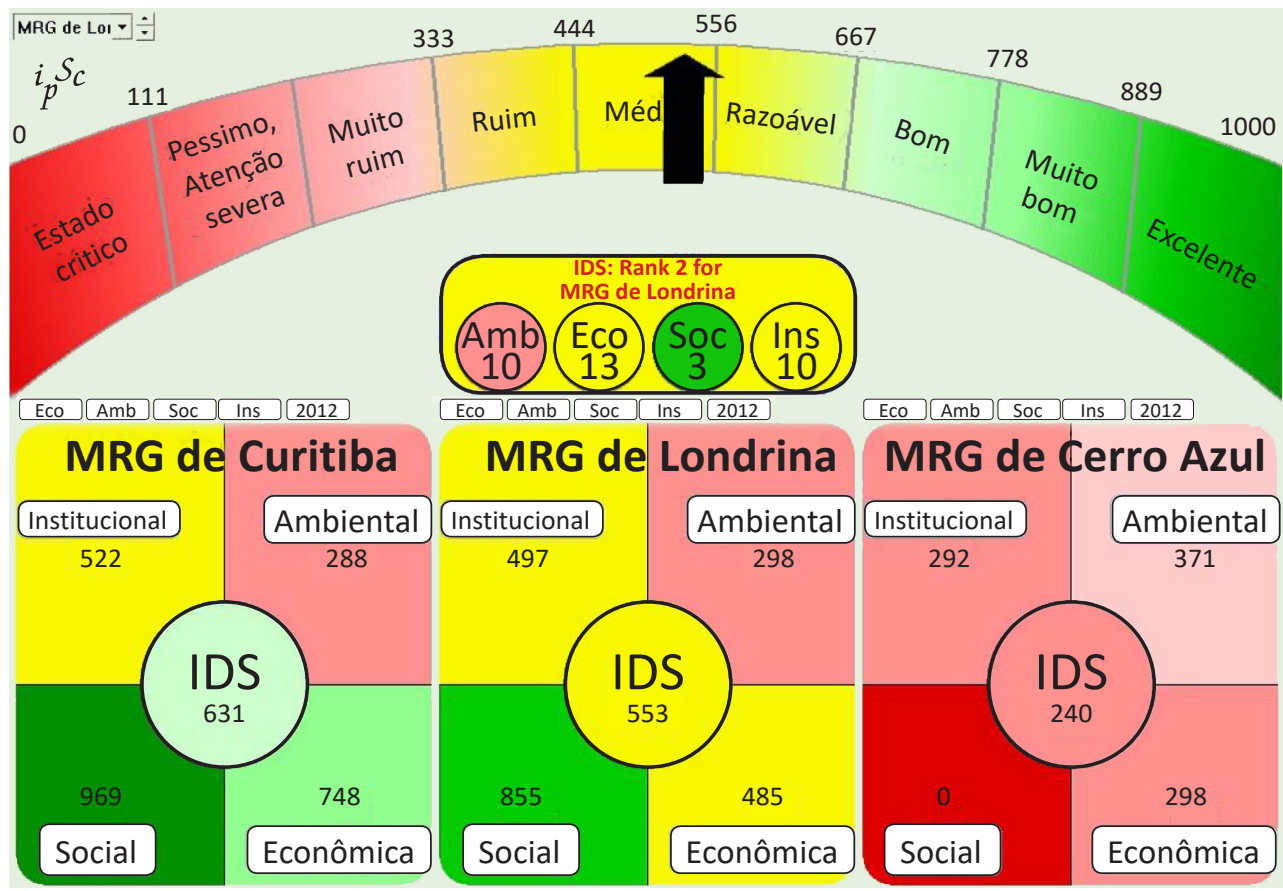

Fonte: dados da pesquisa (2014).

Figura 2. Classificação dos indicadores conforme sua performance

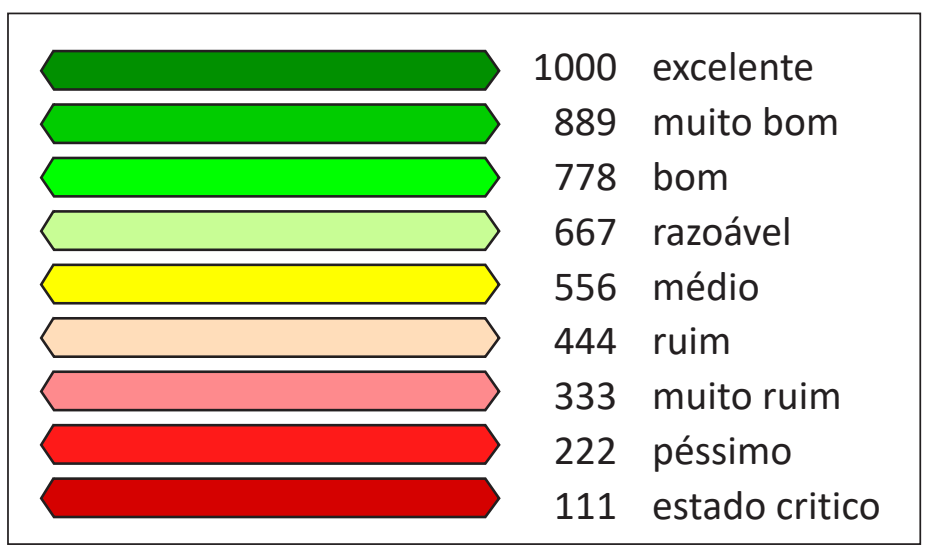

Fonte: adaptado do software Dashboard of Sustainability.

Os indicadores de cada variável para cada microrregião são definidos a partir de uma divisão simples (Equação 1). 


$$
\mathrm{C}=\frac{\mathrm{PM}}{\mathrm{N}}
$$

Em que: $C$ é o tamanho das categorias e indica quantos pontos compõem cada categoria de cor/situação; PM é a pontuação máxima, 1000; N é o número de categorias de classificação das situações.

A classificação dos dados foi estruturada a partir de dois valores extremos (Equação 2).

$$
v=\frac{1000(\mathrm{X}-\mathrm{P})}{\mathrm{M}-\mathrm{P}}
$$

Em que: V é a pontuação das variáveis; $\mathrm{X}$ é o local avaliado (microrregiões); P é o menor valor constante; M é o maior valor.

O maior valor entre os indicadores recebe pontuação 1.000 (mil), e o menor valor recebe pontuação 0 (zero). Todos os indicadores foram comparados com os outros valores parâmetros (o menor e o maior). Em cada variável, foi utilizado o indicador que obteve o maior/menor valor para avaliar a melhor/pior situação entre as microrregiões.

Esse processo foi realizado em todas as variáveis de cada dimensão, comparando as microrregiões pelo sistema do painel. Foram tabulados primeiramente os dados do ano de 2000 e depois do ano 2012.

Como os índices de população são disponibilizados apenas a cada dez anos, utilizou-se a variável referente ao ano 2010 como parâmetro para 2012 nas variáveis em que foi necessário para eliminar o efeito de tamanho da população. As variáveis foram adquiridas nos bancos de dados do Governo do Estado do Paraná e do Governo Federal, dentre eles: Instituto Paranaense de Desenvolvimento Econômico e Social (Ipardes), Ministério da Saúde (DataSUS), Ministério do Trabalho e emprego - Relação Anual de Informações Sociais (MTE-RAIS) e Subprocuradoria-geral de Justiça para Assuntos de Planejamento Institucional (Subplan).

Na dimensão econômica, as variáveis selecionadas foram emprego, frota de veículos, Valor Adicionado Fiscal (VAF) per capita e Produto Interno Bruto (PIB) per capita.

Na dimensão ambiental, as variáveis selecionadas foram atendimento de esgoto, florestas plantadas, florestas nativas e imposto sobre operações relativas à circulação de mercadorias e sobre prestações de serviços (ICMS) de transporte interestadual, intermunicipal e de comunicação ecológico per capita. 
Na dimensão social, as variáveis selecionadas foram abastecimento de água, energia elétrica, densidade demográfica e taxa de pobreza.

E, na dimensão institucional, as variáveis selecionadas foram segurança pública, instituições de crédito, docentes, médicos e comarcas.

\section{ANÁLISE DO IDS DAS MICRORREGIÕES PARANAENSES}

O valor do IDS por MRG ou pontuação, como é chamado pelo sistema, é obtido pela média aritmética simples das quatro dimensões. Estas são obtidas pela média aritmética das variáveis que a compõem. De acordo com os resultados, nenhuma MRG do Paraná obteve um IDS considerado extremamente satisfatório. Em ambos os períodos analisados, o maior índice do Estado se encontrou em situação razoável e, em 2012, foi próxima de uma situação boa.

\subsection{IDS do Estado do Paraná}

Analisando a média de todas as MRGs, obteve-se o IDS do estado do Paraná. Segundo a classificação do Painel de Sustentabilidade, a situação sustentável do Paraná em 2000 era muito ruim. Em 2012, passou a apenas ruim, o que já apresenta uma melhora. Porém, o Estado precisa melhorar muito para atingir um índice ao menos bom, segundo a classificação do sistema (Tabela 1).

\section{Tabela 1. Dimensões e IDS do Estado do Paraná — 2000 e 2012}

\begin{tabular}{|c|c|c|c|c|c|c|c|c|c|c|}
\hline \multirow{2}{*}{ Localidade } & \multicolumn{2}{|c|}{$\begin{array}{l}\text { Dimensão } \\
\text { econômica }\end{array}$} & \multicolumn{2}{|c|}{$\begin{array}{l}\text { Dimensão } \\
\text { ambiental }\end{array}$} & \multicolumn{2}{|c|}{$\begin{array}{c}\text { Dimensão } \\
\text { social }\end{array}$} & \multicolumn{2}{|c|}{$\begin{array}{l}\text { Dimensão } \\
\text { institucional }\end{array}$} & \multicolumn{2}{|c|}{ IDS } \\
\hline & 2000 & 2012 & 2000 & 2012 & 2000 & 2010 & 2000 & 2012 & 2000 & 2012 \\
\hline $\begin{array}{c}\text { Estado do } \\
\text { Paraná }\end{array}$ & 390 & 427 & 201 & 455 & 418 & 225 & 238 & 419 & 327 & 381 \\
\hline
\end{tabular}

Fonte: dados da pesquisa (2014).

Com exceção da dimensão social, todas as dimensões se desenvolveram. A dimensão econômica do Estado melhorou seu desempenho em 9\% entre 2000 e 2012, ainda permanecendo em situação ruim. A dimensão ambiental aumentou sua pontuação em 126\%, sendo a dimensão com maior aumento do índice, passando de situação péssima em 2000 para mediana em 2012. Sua dimensão social caiu 46\% da pontuação, passando de situação ruim para muito ruim, quase entrando na categoria péssima. E a dimensão institucional, que estava em situação muito ruim, aumentou sua pontuação em 17\%, passando a situação ruim. 
Em relação às variáveis que compõem as dimensões (Tabela 2), observa-se que o maior crescimento ocorreu no investimento em segurança pública, em que houve um aumento de $1.170 \%$ em média no Estado. A explicação para esse crescimento expressivo é simples, o investimento era muito baixo em 2000, então, aumentá-lo nessa proporção em 2012 não foi algo tão grandioso quanto o número aparenta; foi uma questão de necessidades básicas sendo atendidas.

Tabela 2. Variação percentual média das quatro dimensões do IDS do Estado do Paraná — $2000 / 2012$

\begin{tabular}{|c|c|c|c|c|}
\hline $\begin{array}{l}\text { Dimensão } \\
\text { econômica }\end{array}$ & $\begin{array}{l}\text { PIB per capita } \\
126 \%\end{array}$ & $\begin{array}{c}\text { Emprego } \\
66 \%\end{array}$ & $\begin{array}{c}\text { Frota de veículos } \\
-163 \%\end{array}$ & $\begin{array}{c}\text { Valor adicionado fiscal } \\
\text { (VAF) per capita } \\
381 \%\end{array}$ \\
\hline $\begin{array}{l}\text { Dimensão } \\
\text { ambiental }\end{array}$ & $\begin{array}{c}\text { ICMS ecológico } \\
278 \%\end{array}$ & $\begin{array}{c}\text { Florestas plantadas } \\
-14 \% \\
\end{array}$ & $\begin{array}{c}\text { Florestas naturais } \\
-96 \\
\end{array}$ & $\begin{array}{c}\text { Atendimento de esgoto } \\
229 \% \\
\end{array}$ \\
\hline $\begin{array}{l}\text { Dimensão } \\
\text { social }\end{array}$ & $\begin{array}{c}\text { Abastecimento } \\
\text { de água } \\
19 \%\end{array}$ & $\begin{array}{c}\text { Energia elétrica } \\
33 \%\end{array}$ & $\begin{array}{c}\text { Densidade } \\
\text { demográfica } \\
6 \%\end{array}$ & $\begin{array}{c}\text { Pobreza } \\
-47 \%\end{array}$ \\
\hline $\begin{array}{l}\text { Dimensão } \\
\text { institucional }\end{array}$ & $\begin{array}{l}\text { Instituições de } \\
\text { crédito } \\
51 \%\end{array}$ & $\begin{array}{c}\text { Segurança pública } \\
1.170 \%\end{array}$ & $\begin{array}{c}\text { Comarcas } \\
-4 \%\end{array}$ & $\begin{array}{l}\text { Docentes } \\
73 \%\end{array}$ \\
\hline
\end{tabular}

Fonte: dados da pesquisa (2014)

Na dimensão econômica, houve mudanças significativas. O VAF per capita foi a variável que mais cresceu e, em consequência, o PIB per capita também cresceu consideravelmente, aumentando o poder de riqueza do Estado que passou de USD\$1 74.750,60 em 2000 para USD\$165.447,14 em 2012. A proporção de empregos formais aumentou significativamente, mas a frota de veículos em relação ao tamanho da população aumentou ainda mais. O que significa que o Estado teve crescimento econômico, mas não sustentável, passando de uma média de um veículo para cada quatro pessoas em 2000 para a média de um veículo para cada duas pessoas em 2012. Todavia, a variação consta como negativa devido ao seu efeito de poluição.

A dimensão ambiental foi a que teve maior evolução no período. O ICMS ecológico aumentou quase 290\%, o que sugere que se passou a investir mais em áreas de preservação; por sua vez, a proporção de domicílios com atendimento de esgoto aumentou cerca de $230 \%$. No entanto, as florestas naturais praticamente desapareceram: em 2012, havia 4\% das florestas naturais existentes em 2000. A variável florestas plantadas também regrediu e, analisando-a juntamente com a de

\footnotetext{
Valores em dólar foram convertidos com base no câmbio de 31 de outubro de 2018, quando USD\$ 1,00 (um dólar) equivalia a aproximadamente R\$ 3,71 (três reais e setenta e um centavos).
} 
florestas naturais, ela deveria ter aumentado a ponto de compensar as perdas de florestas naturais do período.

A dimensão social não sofreu grandes mudanças. Houve mudança expressiva na taxa de pobreza que reduziu em cerca de 50\% com relação a 2000. A variável abastecimento de água cresceu cerca de $20 \%$ em todo o Estado; a variável de energia elétrica teve uma melhora de 33\%, e a densidade demográfica aumentou muito pouco, mantendo-se praticamente igual. A migração entre as regiões do Estado é maior do que entre outros Estados brasileiros.

A mudança mais significativa da dimensão institucional foi em segurança pública, crescendo 1,170\%. Tal aumento se deu graças a algumas MRGs não apresentarem esses dados em 2000 e passarem a apresentar em 2012, possivelmente devido ao investimento preventivo e ao aumento de violência no Estado. A variável de instituições de crédito aumentou cerca de 50\%, indicando que os investimentos do Estado têm crescido. A variável de comarcas apresentou uma queda, pois o número de comarcas que havia em 2000 foi mantido em 2012, enquanto a população aumentou.

\subsection{Análise do IDS das microrregiões paranaenses}

Através do ranking de pontuação e índices das MRGs, observa-se que a maioria das MRGs melhorou seu índice no período; as duas MRGs que se destacaram positivamente foram a de Pato Branco e a de Cianorte, pois foram as regiões que mais se desenvolveram e melhoraram seus índices no período da análise. Enquanto houve quatro casos de piora: as MRGs de Jaguariaíva, de São Mateus do Sul, de Lapa e de Prudentópolis.

Observa-se a classificação das MRGs em um ranking de suas pontuações e índices (Tabela 3) geradas pelo Painel de Sustentabilidade.

Tabela 3. Ranking do IDS das MRGs do Paraná nos anos 2000 e 2012

\begin{tabular}{lcccc}
\hline \multirow{2}{*}{ Microrregião } & \multicolumn{2}{c}{ IDS } & \multicolumn{2}{c}{ Ranking } \\
\cline { 2 - 5 } & 2000 & 2012 & 2000 & 2012 \\
\hline MRG de Curitiba & 599 & 631 & $1^{\circ}$ & $1^{\circ}$ \\
\hline MRG de Londrina & 417 & 553 & $5^{\circ}$ & $2^{\circ}$ \\
\hline MRG de Maringá & 405 & 516 & $7^{\circ}$ & $3^{\circ}$ \\
\hline MRG de Pato Branco & 345 & 499 & $14^{\circ}$ & $4^{\circ}$ \\
\hline MRG de Ponta Grossa & 362 & 495 & $10^{\circ}$ & $5^{\circ}$ \\
\hline MRG de Foz do Iguaçu & 421 & 491 & $4^{\circ}$ & $6^{\circ}$ \\
\hline MRG de Apucarana & 425 & 447 & $3^{\circ}$ & $7^{\circ}$ \\
\hline
\end{tabular}


Samara Cristina Vieceli Piacenti, Jandir Ferrera De Lima e Carlos Alberto Piacenti

\begin{tabular}{|c|c|c|c|c|}
\hline \multirow{2}{*}{ Microrregião } & \multicolumn{2}{|c|}{ IDS } & \multicolumn{2}{|c|}{ Ranking } \\
\hline & 2000 & 2012 & 2000 & 2012 \\
\hline MRG de Palmas & 400 & 438 & $8^{\circ}$ & $8^{\circ}$ \\
\hline MRG de Toledo & 329 & 437 & $17^{\circ}$ & $9^{\circ}$ \\
\hline MRG de Paranaguá & 408 & 435 & $6^{\circ}$ & $10^{\circ}$ \\
\hline MRG de Cascavel & 359 & 433 & $11^{\circ}$ & $11^{\circ}$ \\
\hline MRG de Umuarama & 325 & 431 & $19^{\circ}$ & $12^{\circ}$ \\
\hline MRG de Jacarezinho & 357 & 429 & $13^{\circ}$ & $13^{\circ}$ \\
\hline MRG de Jaguariaíva & 469 & 420 & $2^{\circ}$ & $14^{\circ}$ \\
\hline MRG de Cianorte & 290 & 416 & $27^{\circ}$ & $15^{\circ}$ \\
\hline MRG de Telêmaco Borba & 389 & 416 & $9^{\circ}$ & $16^{\circ}$ \\
\hline MRG de Porecatu & 304 & 372 & $24^{\circ}$ & $17^{\circ}$ \\
\hline MRG de União da Vitória & 359 & 372 & $12^{\circ}$ & $18^{\circ}$ \\
\hline MRG de Astorga & 302 & 367 & $25^{\circ}$ & $19^{\circ}$ \\
\hline MRG de Francisco Beltrão & 282 & 367 & $30^{\circ}$ & $20^{\circ}$ \\
\hline MRG de Paranavaí & 340 & 364 & $15^{\circ}$ & $21^{\circ}$ \\
\hline MRG de Campo Mourão & 306 & 361 & $23^{\circ}$ & $22^{\circ}$ \\
\hline MRG de Cornélio Procópio & 327 & 360 & $18^{\circ}$ & $23^{\circ}$ \\
\hline MRG de Capanema & 262 & 354 & $32^{\circ}$ & $24^{\circ}$ \\
\hline MRG de Wenceslau Braz & 287 & 348 & $28^{\circ}$ & $25^{\circ}$ \\
\hline MRG de Floraí & 323 & 344 & $20^{\circ}$ & $26^{\circ}$ \\
\hline MRG de Irati & 298 & 336 & $26^{\circ}$ & $27^{\circ}$ \\
\hline MRG de Lapa & 339 & 332 & $16^{\circ}$ & $28^{\circ}$ \\
\hline MRG de Guarapuava & 319 & 319 & $21^{\circ}$ & $29^{\circ}$ \\
\hline MRG de Ivaiporã & 214 & 314 & $16^{\circ}$ & $30^{\circ}$ \\
\hline MRG de Goioerê & 234 & 312 & $35^{\circ}$ & $31^{\circ}$ \\
\hline MRG de Assaí & 246 & 308 & $33^{\circ}$ & $32^{\circ}$ \\
\hline MRG de Rio Negro & 285 & 295 & $29^{\circ}$ & $33^{\circ}$ \\
\hline MRG de São Mateus do Sul & 314 & 287 & $22^{\circ}$ & $34^{\circ}$ \\
\hline MRG de Faxinal & 213 & 274 & $38^{\circ}$ & $35^{\circ}$ \\
\hline MRG de Ibaiti & 243 & 259 & $34^{\circ}$ & $36^{\circ}$ \\
\hline MRG de Prudentópolis & 269 & 259 & $31^{\circ}$ & $37^{\circ}$ \\
\hline MRG de Pitanga & 191 & 243 & $39^{\circ}$ & $38^{\circ}$ \\
\hline MRG de Cerro Azul & 195 & 240 & $38^{\circ}$ & $39^{\circ}$ \\
\hline
\end{tabular}

Fonte: dados da pesquisa (2014).

A MRG com melhor IDS e a única em situação positiva foi a de Curitiba. Apesar de ter obtido o maior índice, não foi um índice alto: 599 em 2000, e 631 em 2012, 
mantendo uma pontuação razoável no decorrer dos dois períodos. As demais MRGs apresentaram índices menores, o que demonstra que as regiões estavam de situação péssima a mediana em 2000 e de muito ruim a mediana em 2012, o que indica que, em geral, as MRGs melhoraram seu IDS.

Na Figura 3, é possível observar quais foram as MRGs que se desenvolveram e quais pioraram no período, através de sua situação.

Figura 3. MRGs do Paraná classificadas por situação do IDS, 2000 e 2012

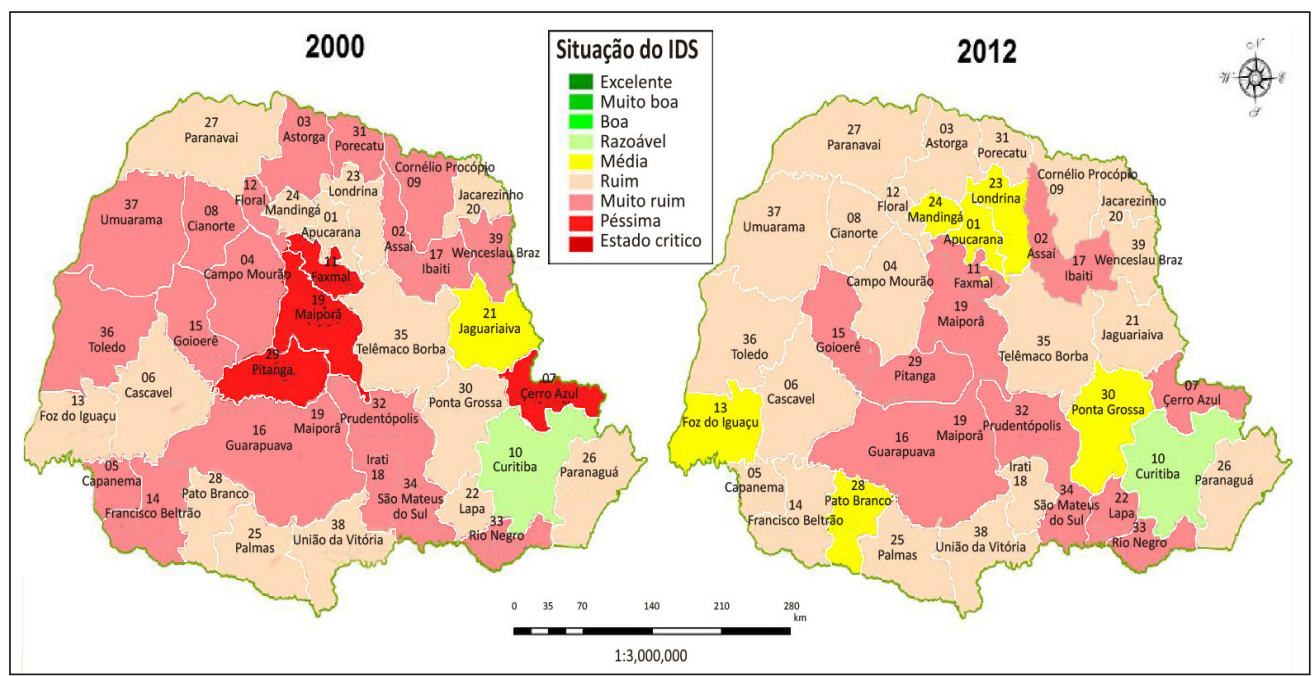

Fonte: dados da pesquisa (2014).

Nota-se que houve certa concentração de MRGs menos desenvolvidas e de MRGs mais desenvolvidas. A região central do Estado permaneceu entre os piores IDS. Já as MRGs periféricas, com exceção das MRGs de Cerro Azul, de Lapa e de São Mateus do Sul, estavam com índices melhores ou, pelo menos, se desenvolveram bastante em relação às MRGs analisadas. A maior redução no IDS foi a MRG de Jaguariaíva, foi a que menos se desenvolveu no período.

Na Figura 4, está representada a ordem dos IDS das MRGs em um gráfico de dispersão, em que cada círculo representa a posição de uma MRG do Paraná. Os diferentes tons dos círculos representam a situação dos IDS no ano de 2000, e os triângulos representam a situação dos IDS no ano de 2012. O eixo Y (vertical) mede o IDS, e as marcas da régua são os pontos que dividem as categorias dos IDS. O eixo X (horizontal) também mede o IDS, apresentando-o com a cor correspondente à situação que a MRG se encontra, de estado crítico a excelente. Portanto, quanto mais alto e a direita estiver a MRG, melhor era sua situação. 
Figura 4. IDS das MRGs do Estado do Paraná, 2000 e 2012

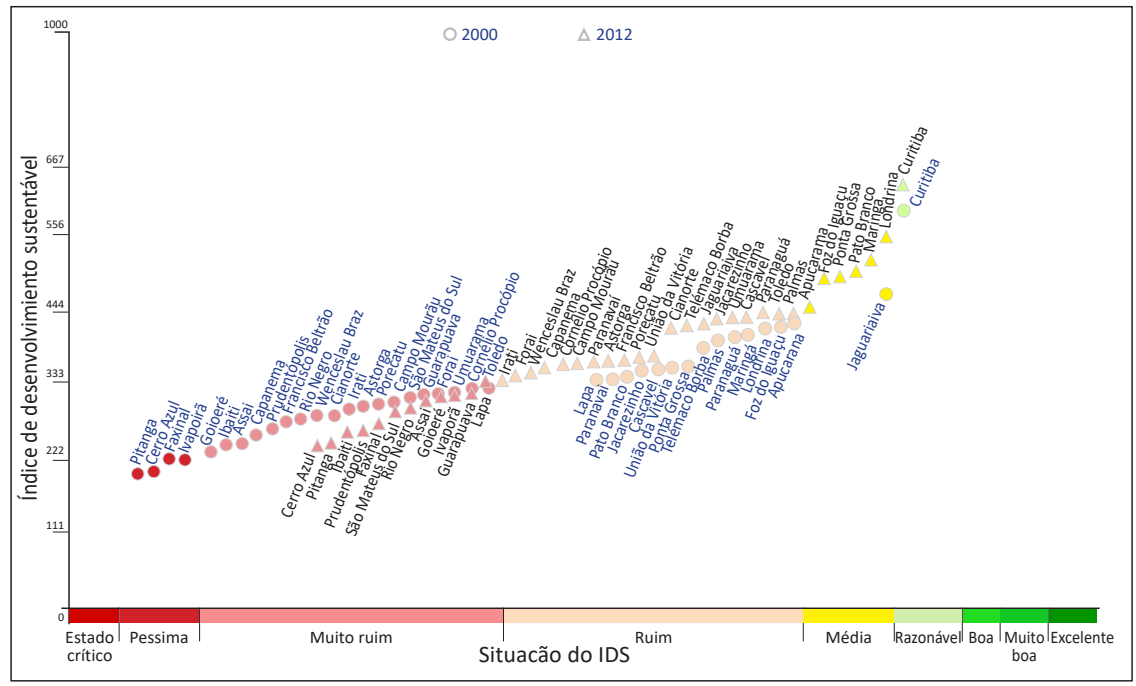

Fonte: dados da pesquisa (2014).

A partir da Figura 4, percebe-se o quanto as MRGs se desenvolveram ao longo do período. Quanto mais próximo o círculo de determinada MRG estiver do triângulo referente a ela, menor terá sido o avanço da MRG entre os dois períodos analisados. E vice-versa, quanto mais longe estiverem, maior terá sido seu desenvolvimento. Quanto mais longe da extrema esquerda estiver o círculo/triângulo daqueles da extrema direita, maiores são as diferenças entre as MRGs.

As MRG referentes a 2000 (círculos) estão muito mais dispersas, portanto houve melhora no decorrer dos períodos, pois, em 2012, os triângulos estão mais aglomerados do que os círculos. Isso indica que, no segundo período, as MRGs estavam mais equilibradas entre si em termos de desenvolvimento sustentável.

A Tabela 4 apresenta os IDS e os índices das quatro dimensões da MRG de Jaguariaíva e MRG de Pato Branco. A que menos se desenvolveu e a que mais se desenvolveu no período, respectivamente.

Tabela 4. Dimensões do IDS das MRGs Jaguariaíva e Pato Branco, 2000 e 2012

\begin{tabular}{|c|c|c|c|c|c|c|c|c|c|c|}
\hline \multirow{2}{*}{ Localidade } & \multicolumn{2}{|c|}{$\begin{array}{l}\text { Dimensão } \\
\text { econômica }\end{array}$} & \multicolumn{2}{|c|}{$\begin{array}{l}\text { Dimensão } \\
\text { ambiental }\end{array}$} & \multicolumn{2}{|c|}{$\begin{array}{c}\text { Dimensão } \\
\text { social }\end{array}$} & \multicolumn{2}{|c|}{$\begin{array}{l}\text { Dimensão } \\
\text { institucional }\end{array}$} & \multicolumn{2}{|c|}{ IDS } \\
\hline & 2000 & 2012 & 2000 & 2012 & 2000 & 2012 & 2000 & 2012 & 2000 & 2012 \\
\hline MRG de Jaguariaíva & 645 & 582 & 668 & 258 & 273 & 447 & 292 & 393 & 469 & 420 \\
\hline MRG de Pato Branco & 369 & 603 & 164 & 529 & 474 & 244 & 376 & 623 & 345 & 499 \\
\hline
\end{tabular}

Fonte: dados da pesquisa (2014). 
Para entender a tabela e o que faz com que algumas MRGs se desenvolvam mais e sejam mais sustentáveis do que outras, é necessário analisar e comparar as dimensões e as variáveis das melhores e das piores MRGs. Suas diferenças apontarão o que precisa ser melhorado para que haja equilíbrio e um padrão entre as MRGs.

Na MRG de Jaguariaíva, enquanto as dimensões social e institucional melhoraram, as dimensões econômica e, principalmente, a ambiental pioraram, resultando em uma baixa de 49 pontos no IDS, assim como na queda de 12 posições no ranking, passando da 2a posição em 2000 para a 14ª em 2012.

Na dimensão econômica, com exceção da frota de veículos, todas as outras variáveis tiveram uma melhora expressiva, ou seja, aumentaram-se o PIB per capita, a proporção da população empregada e o valor da produção do trabalho. No entanto, a pontuação da dimensão é menor no período posterior, porque ela é obtida por meio de comparação com os dados das demais MRGs de 2012 e não leva em conta o quanto ela mudou do ano 2000.

A dimensão ambiental sofreu a maior queda na MRG de Jaguariaíva. A proporção da população com atendimento de esgoto cloacal diminuiu aproximadamente 30\%; a proporção de florestas naturais e de florestas plantadas por habitante diminuiu cerca de $30 \%$ e $90 \%$ respectivamente no primeiro período, sendo as maiores causadoras da queda de pontuação.

A MRG de Pato Branco aumentou 154 pontos e foi a segunda que mais subiu no ranking: passou da $14^{a}$ para a $4^{a}$ posição. Sua situação passou de ruim em 2000 a mediana em 2012.

Observa-se ainda quais os fatores que mais contribuíram para tal mudança. Com exceção da dimensão social, todas as dimensões melhoraram. Na dimensão econômica, apenas a frota de veículos teve piora no índice, pois aumentou a frota de veículos em relação à população em aproximadamente 140\%. Foi a MRG que mais cresceu o número de empregos per capita, cerca de 120\%. O VAF per capita teve um aumento de cerca de $470 \%$, ou seja, o ganho de receita por município aumentou.

A dimensão ambiental teve um aumento expressivo na pontuação geral. Analisando as variáveis que a compõem, apenas o ICMS ecológico e o atendimento de esgoto tiveram seus índices melhores no segundo período, o que significa que a MRG foi mais urbanizada e parte das florestas foi devastada.

A dimensão social cresceu pouco em comparação com as demais MRGs, o que resultou em uma pontuação muito ruim. A variável com maior mudança foi a taxa de pobreza, em que 50\% da população que estava nessa categoria de pobreza em 
2000 conseguiram sair dela em 2012. A variável de abastecimento de água cresceu em $25 \%$ da MRG, passando a atender a quase $80 \%$ da população. A variável energia elétrica cresceu em 30\%, e a de densidade demográfica, $7 \%$.

A dimensão institucional teve um grande crescimento. O número de instituições de crédito em proporção à população aumentou cerca de 60\%, o que passou a incentivar mais os investimentos na MRG. Os investimentos em segurança pública aumentaram em torno de 190\%. Os índices de médicos e de docentes por mil habitantes aumentaram em torno de $120 \%$ e $90 \%$ respectivamente, o que indica que, na saúde e na educação, a microrregião estava em melhores condições em 2012.

\subsection{Dimensões das MRGs com os melhores IDS}

Nesta seção, apresenta-se o desempenho das MRGs paranaenses com os melhores IDS explicados por dimensão.

\subsubsection{Dimensão econômica das MRGs com maiores IDS}

Na maioria das MRGs com melhor IDS, a dimensão que mais se desenvolveu foi a econômica (Tabela 5).

Tabela 5. Pontuação das cinco MRGs com melhores IDS do Paraná na dimensão econômica, 2000 e 2012

\begin{tabular}{lccccccccccc}
\hline \multicolumn{1}{c}{ Variável } & \multicolumn{2}{c}{ PIB per capita } & \multicolumn{2}{c}{ Emprego } & \multicolumn{2}{c}{ Frota de veículos } & VAF per capita & \multicolumn{3}{c}{$\begin{array}{c}\text { Dimensão } \\
\text { econômica }\end{array}$} \\
\hline Localização / Período & 2000 & 2012 & 2000 & 2012 & 2000 & 2012 & 2000 & 2012 & 2000 & 2012 \\
\hline MRG de Curitiba & 900 & 1000 & 810 & 889 & 1000 & 1000 & 0 & 103 & 677 & 748 \\
\hline MRG de Londrina & 494 & 484 & 504 & 430 & 667 & 821 & 42 & 205 & 426 & 485 \\
\hline MRG de Maringá & 384 & 477 & 416 & 425 & 667 & 964 & 0 & 0 & 366 & 466 \\
\hline MRG de Pato Branco & 467 & 909 & 341 & 494 & 296 & 679 & 375 & 333 & 369 & 603 \\
\hline MRG de Ponta Grossa & 691 & 750 & 594 & 446 & 556 & 714 & 417 & 462 & 564 & 593 \\
\hline
\end{tabular}

Fonte: dados da pesquisa (2014).

A variável PIB per capita teve índices em situações variadas em 2000, predominando a situação ruim. Em 2012, a maioria das MRGs reduziu esse valor. Considera-se que foram índices ruins por serem das MRGs de melhores IDS, pois, com exceção das MRGs de Curitiba, que teve pontuação positiva, as demais tiveram pontuações baixas. Por outro lado, a riqueza e outros pontos positivos do Estado não estavam concentrados apenas nas MRGs de melhores IDS. 
Outra MRG que se destacou nessa dimensão foi a de Paranaguá, que obteve o maior PIB per capita nos dois períodos analisados, USD\$3.790,15 em 2000 e USD\$ $8.706,75$ em 2012. Assim como a MRG de Palmas, que teve uma queda muito grande nessa variável, passou da situação razoável a muito boa. Nesse caso, apresentou um crescimento lento, seu PIB per capita em 2000 foi de USD\$2.840,19 e, 12 anos depois, aumentou para USD\$4.258,54.

O desempenho da variável emprego per capita teve os índices do ano 2000 em situações que variaram de muito ruim a excelente. Em 2012, todas as MRGs melhoraram, passando a ter mais pessoas em idade ativa empregadas. Em geral, foi um desempenho muito bom, o que indica que essas MRGs estão entre os menores índices de desemprego do Estado. A MRG com a pontuação máxima nos dois períodos foi Curitiba.

Quanto à variável frota de veículos, na maioria dos casos, ocorreu desempenho negativo em ambos os períodos. Em 2012, a metade dessas MRGs piorou sua pontuação. Como esperado, foram índices muito piores referentes às Microrregiões de piores IDS. Isso significa que havia muitos veículos por habitante, o que é péssimo para o meio ambiente. Em 2000, as MRGs de Curitiba e de Maringá obtiveram a pontuação mínima, indicando que tinham a maior frota de veículos por habitante, em ambas havia cerca de um automóvel para cada três habitantes. Em 2012, apenas a MRG de Maringá permaneceu na última posição, tendo o pior desempenho nessa variável, havia dobrado a proporção automóveis/população, cerca de um automóvel para cada 1,5 habitantes.

A maioria das pontuações do VAF per capita melhorou. Em 2000, as MRGs se encontravam em situações variadas, de ruim a excelente. Em 2012, continuaram muito variadas, o que indica que os ganhos de receita por município dessas regiões estavam entre os mais altos. Em 2000, a MRG de Foz do Iguaçu tinha a maior arrecadação de VAF per capita, porém, em 2012, perdeu a posição, passando-a para a MRG de Curitiba. Logo, Curitiba foi a MRG com o maior ganho de receita por município no período.

\subsubsection{Dimensão ambiental das MRG com maiores IDS}

Em 2000, em Londrina, Maringá, Pato Branco e Ponta Grossa, a variável atendimento de esgoto obteve índices ruins na maioria dos casos, índices péssimos e um de estado crítico; apenas a MRG de Curitiba teve uma pontuação positiva nesse ano. Na MRG de Curitiba, 42\% da população da tinha acesso à rede de esgoto; ainda assim, a MRG obteve um índice considerado bom, menor apenas que o da MRG de 
Jacarezinho, que foi de 50\% da população; mesmo com índices considerados bons, são valores muito baixos de atendimento de saneamento básico. Em 2012, todas as MRGs melhoraram seu desempenho de atendimento de esgoto, aumentando de $10 \%$ a 530\%, com pontuações de muito ruim a razoável. Isso demonstra que havia uma grande disparidade da variável até mesmo entre as MRGs de melhores IDS. A MRG de Londrina obteve a pontuação máxima em 2012, com a maior parcela de domicílios que receberam atendimento de esgoto (77\%).

Já a variável ICMS ecológico, tanto em 2000 quanto em 2012, teve índices muito negativos, de estado crítico ou muito ruim. Em 2000, a MRG de Apucarana teve a pontuação máxima, o que significa que, nesse período, era a que mais investia em áreas de conservação/preservação. Em 2012, todas as MRGs tiveram melhora em sua pontuação.

Em ambos os períodos analisados, as variáveis florestas plantadas e florestas naturais tiveram índices de estado crítico em quase todos os casos, o que indica que praticamente não havia florestas nessas regiões. A MRG de Maringá teve pontuação zero, pois teve a menor área de florestas naturais entre as MRGs. Portanto, juntamente com a variável ICMS ecológico, pode-se concluir que a situação ambiental dessas MRGs estava péssima.

\subsubsection{Dimensão social das MRGs com maiores IDS}

As MRGs de Curitiba, Londrina, Maringá, Pato Branco e Ponta Grossa tiveram desempenho similar nas variáveis taxa de pobreza, abastecimento de água e energia elétrica; elas apresentaram a maioria dos indicadores em situação positiva, o que indica um bom desenvolvimento das MRGs. Tais indicadores sugerem que estas foram as MRGs com menos pobreza, com a maior parcela da população com atendimento de esgoto e maior uso de energia elétrica por domicílio no Paraná, tanto em 2000 quanto em 2012. Em ambos os períodos, as situações são, em geral, boas.

Na variável taxa de pobreza, nota-se que, em 2000, a MRG com a menor taxa de pobreza foi Curitiba, com $28 \%$ de sua população vivendo com até meio salário-mínimo, e, em 2012, passou a ser Maringá, com apenas 11\% da população em situação de pobreza. Na variável abastecimento de água, em 2000, a MRG de Londrina teve a maior parcela da população recebendo esse serviço em 2000, e, em 2012, é a MRG de Curitiba.

Na variável energia elétrica, em 2000, foi a MRG de Curitiba que teve o maior consumo, e, em 2012, foi a MRG de Foz do Iguaçu. Essa variável reflete, de certa 
forma, uma situação econômica também, pois envolve a capacidade de consumo de eletrodomésticos e eletricidade.

Já a variável densidade demográfica ficou com índices de estado crítico em grande parte dos casos. Isso indica que a maioria das MRGs com melhor IDS não era necessariamente aquelas com maior concentração da população, mas sim entre as com menor densidade demográfica. No entanto, as MRGs com maior densidade demográfica (de Curitiba, de Londrina e de Maringá) são as que possuem também as mais altas posições entre os maiores IDS.

\subsubsection{Dimensão institucional das MRGs com maiores IDS}

Nas cinco MRGs (Curitiba, Londrina, Maringá, Pato Branco e Ponta Grossa), a situação predominante era péssima na variável docentes por mil habitantes em 2000. Esses índices sugerem que a educação não era um fator muito investido e incentivado nessas MRGs. Em 2012, a situação das MRGs passou a ser mais diversificada e muitas delas melhoraram seu desempenho, enquanto outras relativamente pioraram muito. Ocorreu algo anormal na MRG de Curitiba: ela recebeu a pontuação máxima (1.000) em 2000 e a pontuação mínima (0) em 2012. Ou seja, no primeiro período, foi a região que tinha mais docentes em relação à população e, 12 anos depois, passou a ser a MRG com o menor número de docentes por habitante, ou seja, ela não acompanhou o aumento do número de docentes que houve nas demais MRGs.

A variável instituições de crédito ficou com índices em situações variadas nos dois períodos analisados. No ano 2000, a maioria dessas MRGs ficou em situação positiva (MRG de Curitiba, de Londrina, de Maringá e de Pato Branco), o que sugere que havia bastante incentivo ao crédito nessas MRGs. Por outro lado, a MRG de Ponta Grossa ficou com pontuação de situação ruim, ou seja, o incentivo ao crédito era pouco na região.

A variável segurança pública, das cinco MRGs de melhor IDS em 2000, teve todos os índices em estado crítico (menor do que 111), ou seja, estavam entre aquelas que menos investiam na segurança pública. Entretanto, em 2012, todos os índices melhoraram, ficaram em situações bastante variadas, de excelente (MRG de Curitiba) a estado crítico (MRG de Pato Branco). No último período, a MRG de Curitiba foi a região com o maior investimento em segurança pública, investiu US\$ 9,81 per capita, quando a média gasta entre essas cinco MRGs foi de USD\$ 4,74 per capita. Já a MRG que menos investiu nesse ponto, foi a de Pato Branco, com um investimento de USD\$ 0,76 per capita. Esse indicador pode refletir tanto investimento por prevenção quanto por índice de violência; portanto, nem sempre pouco investimento em segurança pública significa uma situação ruim, mas pode significar pouca violência na região. 
A variável comarcas por mil habitantes teve a maioria dos índices em estado crítico em ambos os períodos, o que indica que a situação da administração da justiça nessas regióes era extremamente fraca, com poucas comarcas para muita população. Em 2000, a única MRG das cinco de melhor IDS a ter um índice melhor, médio no caso, foi a de Pato Branco, e a MRG de Curitiba teve a menor pontuação tanto em 2000 quanto em 2012, tendo sido, assim, a MRG com o menor número de comarcas em relação à população.

A variável médicos por mil habitantes, em 2000, teve apenas um índice positivo, o da MRG de Curitiba, com 610 pontos, uma pontuação considerada média. Os demais índices estavam em situação negativa. Em 2012, todas as cinco MRGs passaram a ter índices positivos. O caso que teve o maior crescimento foi o da MRG de Ponta Grossa, que aumentou 651 pontos e subiu cinco posições, passando de situação péssima a boa.

\subsection{MRGs paranaenses com os piores IDS}

Nesta seção, apresenta-se o desempenho das MRGs paranaenses com os menores IDS explicados por dimensão.

\subsubsection{Dimensão econômica das MRGs com menores IDS}

Observa-se, na Tabela 6, a pontuação de cada variável da dimensão econômica das cinco MRGs de piores IDS no estado do Paraná.

Tabela 6. Pontuação das cinco MRGs com piores IDS do Paraná na dimensão econômica, 2000 e 2012

\begin{tabular}{lccccccccccc}
\hline \multicolumn{1}{c}{ Variável } & PIB per capita & \multicolumn{2}{c}{ Emprego } & \multicolumn{2}{c}{ Frota de veículos VAF per capita } & \multicolumn{2}{c}{$\begin{array}{c}\text { Dimensão } \\
\text { econômica }\end{array}$} \\
\hline Localização / Período & 2000 & 2012 & 2000 & 2012 & 2000 & 2012 & 2000 & 2012 & 2000 & 2012 \\
\hline MRG de Cerro Azul & 0 & 0 & 0 & 193 & 0 & 0 & 1000 & 1000 & 250 & 298 \\
\hline MRG de Pitanga & 105 & 194 & 52 & 29 & 37 & 0 & 958 & 769 & 288 & 248 \\
\hline MRG de Prudentópolis & 217 & 276 & 102 & 12 & 185 & 143 & 792 & 667 & 324 & 274 \\
\hline MRG de Ibaiti & 132 & 46 & 120 & 0 & 148 & 143 & 792 & 795 & 298 & 246 \\
\hline MRG de Faxinal & 174 & 392 & 155 & 115 & 148 & 179 & 667 & 590 & 286 & 319 \\
\hline
\end{tabular}

Fonte: dados da pesquisa (2014).

Os valores de VAF per capita foram, em sua maioria, ruins nos dois períodos. Isso significa que os ganhos de receita por município dessas MRGs estavam entre 
os mais baixos. Como o VAF é resultado do trabalho humano, pode-se dizer que a produção de mercadorias tributáveis gerada era baixa, afinal as arrecadações foram as mais baixas do Estado. A MRG de Cerro Azul teve o pior índice nos dois períodos, o que indica que tinha o pior ganho de receitas por município de todo o Estado.

Já as variáveis PIB per capita e emprego per capita tiveram índices similares, ambos foram muito ruins, péssimos ou até de estado crítico nos dois períodos analisados. Mais uma vez, estas foram as MRGs com os piores índices, o que significa que estavam entre as regiões mais pobres do Estado e eram aquelas com maiores índices de desemprego. Em 2000, a MRG de Cerro Azul teve a pior pontuação em ambas as variáveis, pois era a MRG mais pobre, com a maior parte da população em situação de pobreza. Em 2012, a MRG de Ibaiti obteve o pior PIB per capita, e a MRG de Cerro Azul junto com a MRG de Pitanga obtiveram o pior índice de emprego per capita.

Notou-se que a variável frota de veículos teve índices razoáveis e muito bons na maioria dos casos. Isso significa que a proporção de automóveis por habitante era pequena, ou seja, havia relativamente poucos veículos por habitante em ambos os períodos analisados, o que é muito bom para o meio ambiente. A MRG de Cerro Azul obteve a pontuação máxima em 2000 e em 2012, o que indica que obteve a menor frota de veículos por habitante, tendo assim o melhor desempenho nessa variável. Em 2000, havia um automóvel para cada 12,5 habitantes e, em 2012, um automóvel para cada 3,4 habitantes. Esses números mostram que, mesmo Cerro Azul, a MRG que menos se desenvolveu de 2000 para 2012, passou a ter muito mais veículos.

\subsubsection{Dimensão ambiental das MRGs com menores IDS}

Em Cerro Azul, Pitanga, Prudentópolis, Ibaiti e Faxinal, as variáveis atendimento de esgoto por domicílio e de ICMS ecológico per capita tiveram índices de situação péssima, muito ruim ou em estado crítico em sua maioria, nos dois períodos analisados. A MRG que obteve o índice mais baixo de atendimento de esgoto foi a de Cerro Azul, nos dois períodos, praticamente não havia esse serviço. Já a variável ICMS ecológico, em 2000, em quase todas as MRGs, estava em situação de estado crítico, praticamente não se investia em áreas de conservação. Em 2012, houve ao menos uma pequena melhoria nas MRGs. A melhor pontuação foi da MRG de Cerro Azul, que apresentou o maior repasse de recursos financeiros aos municípios que abrigam alguma unidade de conservação. 
As variáveis florestas plantadas e florestas naturais tiveram índices de estado crítico na grande maioria dos casos. Em 2000, em geral, havia muito mais florestas do que em 2012, especialmente florestas naturais. A MRG de Cerro Azul foi a única das cinco que aumentou as plantações de florestas um pouco mais do que as demais. De forma semelhante, mas obviamente com maior contraste, em 2000, havia muito mais florestas naturais do que em 2012. Das pontuações que melhoraram, a MRG de Pitanga não aumentou o número de florestas naturais, mas foi desmatado menos do que nas demais MRGs. Já a MRG de Ibaiti teve a menor pontuação, com a menor área de florestas naturais em relação ao tamanho da população.

\subsubsection{Dimensão social das MRGs com menores IDS}

As MRGs de piores IDS foram Cerro Azul, Pitanga, Prudentópolis, Ibaiti e Faxinal. A MRG de Cerro Azul teve o pior índice em todas as variáveis de toda a dimensão nos dois períodos. Foi a microrregião que menos tinha o serviço água potável, tinha o mais baixo consumo de energia elétrica, teve a maior taxa de pobreza e era a microrregião com menor densidade demográfica.

A variável taxa de pobreza, no ano 2000, teve índices muito ruins na maioria dos casos, o que significa que essas MRGs estavam entre aquelas com as maiores taxas de pobreza do Estado. Em 2012, os índices melhoraram bastante, ficaram em situações variadas, de médio a estado crítico, mas em sua maioria foram ruins.

A variável abastecimento de água também obteve índices de situações bem variadas, de razoável a péssima em 2000 e de boa a ruim em 2012, com exceção do caso da MRG de Cerro Azul que foi de estado crítico. No ano 2000, apenas a MRG de Ibaiti tinha uma parcela razoável de domicílios que recebia água potável, cerca de $60 \%$ dos domicílios. As outras quatro MRGs de pior IDS ficaram com índices negativos nesse período, cerca de 40\% dos domicílios em 2000 e de 50\% em 2012. Em 2012, as mesmas MRGs que estavam melhores em 2000 continuaram sendo as únicas em situação positiva. Pode-se dizer que foi um resultado razoavelmente bom, pois os piores índices não estão concentrados apenas nessas MRGs, o que seria um problema muito grave e difícil de se recuperar.

Já nas variáveis energia elétrica e densidade demográfica, predominou a situação péssima nessas MRGs; elas tiveram um consumo extremamente baixo de energia elétrica e eram regiões com poucos habitantes por km².

\subsubsection{Dimensão institucional das MRGs com menores IDS}

Na pontuação das variáveis da dimensão institucional das cinco MRGs de piores IDS (Cerro Azul, Pitanga, Prudentópolis, Ibaiti e Faxina), a variável docentes por mil 
habitantes obteve a maioria dos índices em situação péssima em 2000, o que significa que, nesse período, essas MRGs estavam entre as que tinham menos professores em relação à população e não havia incentivo aos estudos. Em 2012, o quadro mudou bastante; os índices ficaram em situações bem variadas, de excelente a ruim, mas pode-se considerar que tiveram na média um desempenho positivo; afinal, essas são as MRGs de pior IDS, e o quadro de professores delas melhorou muito, deixando de fazer parte das MRGs que tinham menos professores por mil habitantes para algumas delas ficarem entre as que mais tinham professores por mil habitantes.

A variável instituições de crédito também ficou com índices em situações variadas, situações de estado crítico a boa em 2000 e, em 2012, quase todas as MRGs melhoraram sua situação. Em 2000, todas as MRGs ficaram em situação negativa. A MRG de Cerro Azul teve a pontuação mínima, sendo a que tinha menos instituições de crédito do Estado. Em 2012, pode-se considerar que houve um incentivo ao crédito a um nível mediano, mas houve vários grandes crescimentos nessa variável.

Já a variável segurança pública teve praticamente todos os índices em situação de estado crítico nos dois períodos, o que demonstra que o investimento com segurança pública era extremamente baixo nessas microrregiões. Em 2000, não foi possível obter os dados de algumas MRGs, mas nota-se que, naquelas que foi possível obtê-los, estavam todas em estado crítico. Em 2012, a situação não melhorou, alguns números cresceram um pouco, mas a maioria permaneceu em situação de estado crítico. A MRG de Ibaiti teve a pontuação mínima em 2012, sendo a que menos investiu em segurança pública. Pode ser que esse baixo investimento em segurança pública seja reflexo de baixo índice de violência nessas MRGs.

Com a variável comarcas por mil habitantes foi o contrário, teve índices muito bons. Em 2000, os índices foram variados de estado crítico a boa, mas a situação da maioria foi mediana. Já em 2012, as cinco MRGs melhoraram e subiram de classificação. Nesse caso, essas MRGs ficaram entre as que tinham mais comarcas em relação à população e, portanto, tinha grande capacidade de administração da justiça.

A variável médicos por mil habitantes teve quase todos os índices em situação péssima nos dois períodos, o que sugeriu que estas fossem as regiões com o menor número de médicos em relação à população, que não houvesse médicos o suficiente para atender às necessidades dessas MRGs. A MRG de Rio Negro foi uma MRG com que também teve baixo IDS, porém obteve a pontuação máxima (1.000 pontos) nos dois períodos nessa varável, ou seja, foi a MRG que mais tinha médicos em relação ao tamanho da população. Todavia, as MRGs de pontuação mínima nessa variável também fazem parte do grupo das MRGs de pior IDS. Em 2000, foi a MRG de Cerro 
Azul, que teve a pontuação mínima e, em 2012, foi a de Pitanga que teve o menor número de médicos em relação ao tamanho da população.

\section{CONCLUSÃO}

Este estudo analisou o desenvolvimento sustentável das MRGs do Paraná nos anos de 2000 e 2012. Para criar os índices, foi utilizado o Painel de Sustentabilidade com quatro dimensões: econômica, ambiental, social e institucional.

O Painel de Sustentabilidade calcula a pontuação das variáveis pela média aritmética simples. Os resultados obtidos indicam que, em 2000, a situação do desenvolvimento sustentável das MRGs era muito ruim. A MRG mais desenvolvida nesse período (2000-2012) foi a de Curitiba, cujo desempenho social foi excelente (o melhor do Estado), o desempenho econômico foi satisfatório, o institucional foi médio e o ambiental foi péssimo. Ou seja, é a MRG mais desenvolvida economicamente, porém não é a que se desenvolveu de forma sustentável, pois seu desempenho ambiental é péssimo. Para o desenvolvimento ser sustentável, deve haver equilíbrio entre as dimensões.

Praticamente o contrário ocorreu na MRG de Pitanga. No primeiro período, ela teve o pior IDS, ou seja, apresentou o desempenho sustentável mais fraco entre as 39 MRGs e o segundo pior desempenho social do Estado, ficando melhor apenas que a MRG de Cerro Azul. O desempenho de suas demais dimensões foram todos insatisfatórios, assim como no caso de quase metade das MRGs nesse período (2000).

No segundo período (2012), os resultados das MRGs se equilibraram um pouco nas quatro dimensões em relação ao período de 2000. Um grande contraste que se pode notar claramente foi que a MRG de Curitiba, a que teve o melhor IDS, ou seja, a MRG mais desenvolvida, fica exatamente ao lado da MRG de pior IDS, a MRG de Cerro Azul, que, por sinal, em 2000, já estava entre as MRGs de pior situação sustentável.

Todavia, em ambos os períodos, a dimensão ambiental se encontrou menos desenvolvida do que as demais, devido principalmente ao desmatamento das florestas e à falta de reflorestamento. Já a dimensão social foi a mais desenvolvida nos dois períodos em geral entre as MRGs. No entanto, a dimensão apresentou uma enorme disparidade entre as MRGs, onde aquelas de maiores IDS tiveram situação social muito satisfatória, e aquelas de menores IDS tiveram essa situação preocupantemente insatisfatória. 
Mesmo com avanço no desenvolvimento sustentável ao longo do período, as MRGs, em geral, ficaram em situação ruim. O IDS do Paraná se encontrou em situação ruim em 2012, mas pode ser melhorado. Como o desenvolvimento sustentável é um processo de longo prazo, pode-se dizer que o Estado está começando a trilhar o caminho correto.

Para auxiliar o desenvolvimento ambiental, uma sugestão seria uma maior cobertura do atendimento de esgoto, até que seja completo em primeiro lugar por se tratar de saneamento básico. Outra medida que pode ser tomada é uma maior preservação das áreas de conservação e incentivo à plantação de florestas por meio de políticas agrícolas.

Para o desenvolvimento social, uma sugestão seria diminuir a taxa de pobreza, o que geraria maior consumo e abrangeria uma maior parcela da população, a qualidade de vida da população aumentaria, e os índices de viroses e doenças diminuiriam.

A sugestão para auxiliar o desenvolvimento institucional seria voltar as atenções para a saúde e a educação. Formar e preparar mais médicos e professores, investir na manutenção e criação de hospitais e instituições públicas de ensino, afinal, tanto a educação quanto a saúde são ferramentas que muito têm a contribuir para o desenvolvimento do Estado, por meio de pesquisas, tratamentos de saúde ou outras contribuições importantes.

O processo de desenvolvimento econômico e sustentável deve ser complementar, jamais em direções opostas. Se caminharem em direções opostas e houver apenas desenvolvimento econômico, este não será durável, pois faltará qualidade de vida para a população e trará consequências negativas para o meio ambiente. A ideia de desenvolvimento sustentável veio justamente para evitar esse problema, para criar meios de se desenvolver economicamente sem esgotar o meio ambiente, preservar a qualidade deste e possibilitar a equidade social. Contudo, para que isso ocorra, são necessários ações políticas e principalmente tempo; afinal, o desenvolvimento é um processo de longo prazo.

\section{REFERÊNCIAS}

Alves, Lucir Reinaldo e Ferrera De Lima, Jandir (2007). Desenvolvimento Sustentável: elementos conceituais e apontamentos para reflexão. Em: Revista Integração, ano XIII, No. 50, jul./ ago./set., p. 141-148.

Barbosa, Gisele Silva (2008). Desafio do Desenvolvimento Sustentável. Em: Revista Visões, Vol. 1, No. 4, janeiro-junho, $11 \mathrm{p}$. 
Benetti, Luciana Borba (2006). Avaliação do Índice de Desenvolvimento Sustentável (IDS) do município de Lages/SC através do método do Painel de sustentabilidade. Tese para optar ao título de doutora em Engenharia Ambiental. Doutorado em Engenharia Ambiental, Universidade Federal de Santa Catarina, Florianópolis, SC, 215p.

Bossel, Hartmut (1999). Indicators for Sustainable Development: Theory, Method, Applications. A Report to the Balaton Group. Winnipeg, Manitoba, 138p.

Bourscheidt, Deise Maria e Dalcomuni, Sônia Maria (2010). Do crescimento econômico ao desenvolvimento sustentável: aspectos conceituais e marcos importantes. Congrega. Alegrete: Urcamp, 16p.

Commission Brundtland (1987). Our Common Future, Brundtland Report. United Nations, General Assembly. Report of the World Commission on Environment and Development, 247p.

IBGE - Instituto Brasileiro de Geografia e Estatística (2012). Em: Indicadores de desenvolvimento sustentável. Rio de Janeiro, RJ.

Ipardes — Instituto Paranaense de Desenvolvimento Econômico e Social (2014). Em: Base de dados do Estado.

Jara, Carlos Júlio (1998) A sustentabilidade do desenvolvimento local. Desafios de um processo em construção. Secretaria de Planejamento do Estado de Pernambuco, Recife, PE, 316p.

Layrargues, Philippe Pomier (1997). Do ecodesenvolvimento ao desenvolvimento sustentável: evolução de um conceito. Em: Revista Proposta, No. 71, dezembro-fevereiro, p. 5-10.

Mcdonough, William e Partners (1992). The Hannover Principles design for Sustainability. Hannover, Germany, Expo 2000. The World's Fair, 59p.

Ministério da Saúde. Informações de Saúde. (2010). Em: Proporção de pessoas com baixa renda - Paraná, 2000, 2010. DataSUS.

Ministério do Trabalho e Emprego (2014). Relação Anual de Informações Sociais (MTE-RAIS). Em: Banco de Dados.

Romeiro, Ademar Ribeiro; Reydon, Bastiaan Philip e Leonardi, Maria Lúcia Azevedo (1999). Economia do meio ambiente: teoria, políticas e a gestão de espaços regionais. 2. ed. Campinas: Unicamp: Instituto de Economia, 377p.

Van Bellen, Hans Michael (2003). Desenvolvimento Sustentável: uma descrição das principais ferramentas de avaliação. Em: Ambiente E Sociedade, Vol. 7, No. 1, janeiro-junho, p. 67-88. 